Julian Nusser

\title{
Die Bindung der Mitgliedstaaten an die Unionsgrundrechte
}

\author{
Vorgaben für die Auslegung von Art. 51 Abs. 1 S. 1 EuGrCh
}

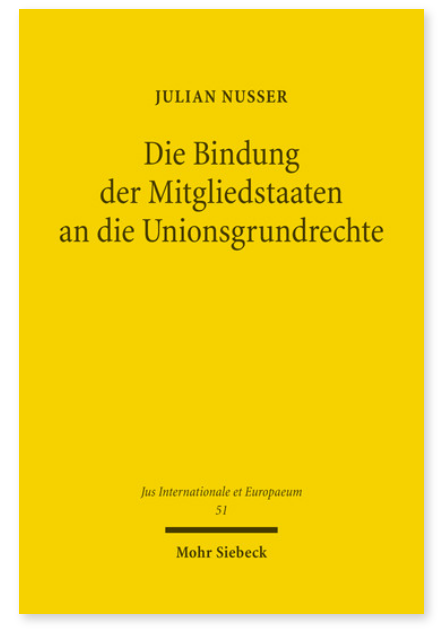

2011. XVIII, 239 Seiten. JusIntEu 51

ISBN 978-3-16-151190-5

DOI 10.1628/978-3-16-151190-5

eBook PDF 69,00€

ISBN 978-3-16-150872-1

fadengeheftete Broschur 69,00€
Unter welchen Voraussetzungen und in welchen Grenzen sind die Mitgliedstaaten an die Unionsgrundrechte gebunden? Zur Beantwortung der Frage setzt sich Julian Nusser mit der einschlägigen Rechtsprechung des Europäischen Gerichtshofes, dem Schrifttum und der Bedeutung von Art. 51 Abs. 1 S.1 EuGrCh auseinander. Er analysiert die Prinzipien, die der Bindung der Mitgliedstaaten an die Unionsgrundrechte zugrundeliegen, um darauf aufbauend einen eigenenen Ansatz zum Untersuchungsgegenstand zu entwickeln. Insoweit sieht er im 'Beruhen' der mitgliedstaatlichen Unionsgrundrechtsbeeinträchtigung auf unionaler Hoheitsgewalt das maßgebliche Kriterium. Schließlich setzt der Autor dieses Kriterium anhand von Fällen, die vom Europäischen Gerichtshof entschieden wurden, zu bisher vertretenen Positionen ins Verhältnis und legt Art. 51 Abs. 1 S. 1 EuGrCh entsprechend aus.

Julian Nusser Geboren 1980; 2001-07 Studium der Rechtswissenschaft in Trier und Lausanne; 2007-09 wissenschaftlicher Mitarbeiter an der Universität Trier; 2010 Promotion; 2009-11 Rechtsreferendariat in Hamburg und Brüssel.

Jetzt bestellen:

https://mohrsiebeck.com/buch/die-bindung-der-mitgliedstaaten-an-die-unionsgrundrechte-9783161511905?no_cache=1 order@mohrsiebeck.com

Telefon: +49 (0)7071-923-17

Telefax: +49 (0)7071-51104 